\title{
Formação de diretores escolares para o Programa Saúde na Escola:
}

\author{
uma pesquisa-ação
}

\author{
VERAS, Karlla da Conceição Bezerra Brito (Fortaleza, Ceará, Brasil) ${ }^{1 *}$ \\ FERREIRA, Heraldo Simões (Fortaleza, Ceará, Brasil) 2 $^{\text {t* }}$ \\ LOURINHO, Lídia Andrade (Fortaleza, Ceará, Brasil) 3 $^{* * *}$ \\ ${ }^{1}$ Universidade Estadual do Ceará, Programa de Pós-Graduação em Cuidados Clínicos em \\ Enfermagem e Saúde, Doutorado em Cuidados Clínicos em Enfermagem e Saúde \\ ${ }^{2}$ Universidade Estadual do Ceará, Programa de Pós-Graduação em Educação, \\ Curso de Mestrado e Doutorado em Educação \\ ${ }^{3}$ Universidade Estadual do Ceará, Programa de Pós-Graduação em Saúde Coletiva, \\ Curso de Mestrado Profissional Ensino na Saúde \\ ORCID ID: https://orcid.org/0000-0001-7464-1992* \\ ORCID ID: https://orcid.org/0000-0003-1999-7982** \\ ORCID ID: https://orcid.org/0000-0002-5883-9007**
}

\begin{abstract}
Resumo
Objetivou-se analisar um processo de formação sobre as características do Programa Saúde na Escola com diretores escolares. O estudo foi realizado com uma pesquisa-ação em abordagem qualitativa. O cenário de estudo foi 0 município de São Benedito, Ceará. Os participantes da pesquisa foram dez diretores de escolas públicas. $\mathrm{Na}$ fase I, diagnosticou-se, após a análise das respostas, que $90 \%$ dos diretores conheciam a existência do referido programa. $\mathrm{Na}$ fase II, empreendeu-se uma ação no formato de formação sobre o Programa Saúde na Escola. Na fase III, ocorreu a entrevista em grupo com os diretores participantes da formação, em que relataram que a formação foi excelente, prática, objetiva e dinâmica. Os resultados da pesquisa indicaram que a formação sobre o mencionado programa contribui expressivamente para a transformação das práticas profissionais, constituindo-se como uma estratégia essencial para o aprimoramento das ações do Programa Saúde na Escola.
\end{abstract}

\section{Palavras-chave}

Saúde na escola. Educação escolar. Educação para a saúde.

\section{Training of school directors for the School Health Program:}

\section{a research-action}

\begin{abstract}
The objective was to analyze a training process on the characteristics of the Health at School Program with school principals. The study was carried out with an action research in a qualitative approach. The study scenario was the municipality of São Benedito, Ceará. The research participants were ten public school principals. In phase I, after analyzing the responses, it was diagnosed that $90 \%$ of the directors knew about the program. In phase II, an action was taken in the format of training on the Health at School Program. In phase III, there was a group interview with the directors participating in the training, in which they reported that the training was excellent, practical, objective and dynamic. The research results indicated that the training on the mentioned program contributes significantly to the transformation of professional practices,
\end{abstract}


constituting itself as an essential strategy for the improvement of the actions of the Health at School Program.

\title{
Keywords \\ Health at school. Schooling. Health education.
}

\section{Formación de directores escolares para el Programa Salud en la Escuela: una investigación-acción}

\begin{abstract}
Resumen
Se objetivó analizar un proceso de capacitación sobre las características del Programa Salud en la Escuela con directores de escuelas. El estudio se realizó cono una investigación de acción en un enfoque cualitativo. El escenario de estudio fue el municipio de São Benedito, Ceará. Los participantes de la investigación fueron diez directores de escuelas públicas. En la fase I, se diagnosticó, después de analizar las respuestas, que el $90 \%$ de los directores conocían el programa. En la fase II, se tomó una acción en el formato de capacitación sobre el Programa Salud en la Escuela. En la fase III, hubo una entrevista grupal con los directores que participaron en la capacitación, en la cual informaron que la capacitación fue excelente, práctica, objetiva y dinámica. Los resultados de la investigación indicaron que la capacitación en el programa mencionado contribuye significativamente a la transformación de las prácticas profesionales, constituyéndose como una estrategia esencial para la mejora de las acciones del Programa Salud en la Escuela.
\end{abstract}

Palabras clave

Salud en la escuela. Educación escolar. Educación para la salud.

\section{Introdução}

É crescente o enfoque da temática saúde da população escolar. Dessa forma, as escolas se tornaram locais privilegiados para serem realizadas estratégias de educação em saúde, entendida como uma ferramenta para a consecução da saúde de escolares.

O ambiente escolar é um espaço propício ao desenvolvimento de práticas educativas que visem à promoção e à prevenção da saúde, compreendendo que estas mantêm relação com a qualidade de vida dos indivíduos e que esse cenário, por se tratar de um ambiente formador de conhecimentos e opiniões, deve abordar essa temática, a fim de formar sujeitos críticos (FERREIRA, 2012).

Sob esse viés, a escola é um dos locais para articular vários setores da sociedade, onde poderão ser desenvolvidos programas de promoção e educação em 
saúde (FIALHO; SANTANA; BRANDENBURG, 2015). É o local ideal para realizar ações em saúde, trabalhando em consideração às necessidades de cada estudante.

Diante disso, por consequência, ocorreu a necessidade da implantação do Programa Saúde na Escola (PSE). O PSE foi implantado em 2007, por meio do Decreto Presidencial ํㅡ 6.286/2007, caracterizando-se como uma parceria entre 0 Ministério da Educação e o Ministério da Saúde, constituindo-se como uma política intersetorial que objetiva contribuir positivamente para a formação de estudantes e profissionais de saúde e educação, bem como possibilitar a promoção, prevenção e atenção à saúde (BRASIL, 2007).

Dessa forma, o PSE prevê as ações de educação em saúde, prevenção, tratamento e manutenção da saúde dos educandos da rede pública, além da capacitação dos profissionais envolvidos nas ações relacionadas ao PSE. O programa traz a necessidade da adoção de temáticas de saúde em sala de aula, usando a participação espontânea e lúdica dos aprendizes. Assim, há a necessidade de um processo de formação permanente com os profissionais envolvidos com o programa, devido às mudanças constantes no cotidiano dos serviços, melhorando a qualidade de assistência prestada à comunidade escolar.

Partindo desse princípio, as reflexões aqui apresentadas despertaram os seguintes questionamentos: um processo de formação sobre as características do PSE, com diretores de escolas, torna-se eficaz no que se refere a capacitar para a prática? Qual o conhecimento dos envolvidos no estudo sobre o PSE?

Nessa perspectiva, a presente pesquisa apresenta como objetivo analisar um processo de formação sobre as características do PSE com diretores escolares no município de São Benedito, Ceará (CE). Assim, os profissionais iniciantes no PSE devem ser qualificados para realizarem as atividades do programa.

\section{Metodologia}

O presente estudo é uma pesquisa-ação com abordagem qualitativa. Thiollent (2011) defende a utilização da pesquisa-ação no campo da educação, pois ela propõe o comprometimento dos pesquisadores com as causas populares, na busca por soluções ou, ao menos, por esclarecimento de problemas. 
No tocante à pesquisa qualitativa, Minayo (2010) retrata que esta tem como função investigar os assuntos em profundidade, avaliando os fatores emocionais e intencionais implícitos nos posicionamentos e comportamentos dos entrevistados, revelando processos sociais ainda pouco conhecidos, referentes a grupos particulares, e propiciando, ao longo da investigação, a construção de novas abordagens, revisão e criação de conceitos e categorias.

O estudo foi realizado no município de São Benedito-CE. Das 51 escolas cadastradas no PSE do município, dez foram selecionadas para participar da pesquisa, devido ao fato de que esses ambientes de ensino estão inseridos no território de atuação de diretores que irão iniciar suas atividades no PSE, fato preponderante para os envolvidos participarem da pesquisa.

A coleta de dados na pesquisa-ação, tal como estabelece Thiollent (2011), estipula as seguintes fases: diagnóstico, planejamento/ação e avaliação. Na primeira fase da pesquisa, verificou-se o conhecimento dos profissionais participantes sobre 0 PSE. Para tanto, recorreu-se à técnica de questionário.

$\mathrm{Na}$ segunda fase da coleta de dados, executaram-se o planejamento e a ação. $\mathrm{O}$ planejamento da ação foi realizado a partir dos dados da primeira fase. A ação em si constou de uma formação sobre o PSE com carga horária de dez horas. Nessa fase, a técnica de coleta foi observação participante, em que se utilizou um roteiro de observação mediante o qual pesquisador e profissionais envolvidos no PSE atuaram de forma cooperativa e participativa. Também se empregou o diário de campo para possibilitar a sistematização das informações.

$\mathrm{Na}$ fase três, realizou-se a avaliação dos diretores envolvidos na pesquisa por meio de uma entrevista em grupo, quando também se avaliaram a formação e a sua efetividade na prática do PSE.

Para a análise dos dados no que se refere à verificação do perfil acadêmico e profissional dos participantes e ao diagnóstico do conhecimento acerca do PSE, na primeira fase, realizou-se uma análise interpretativa dos dados. Já na segunda fase, empreendeu-se a análise subjetiva interpretativa dos dados observados no diário de campo. A análise da fase três foi realizada mediante a análise temática de Minayo (2010), que é definida como a descoberta dos núcleos de sentidos que constituem uma comunicação acerca da frequência ou da presença de algum significado para o objeto 
que está sendo analisado, sendo composta por pré-análise, exploração de todo material disponível e categorização por meio de temas das falas dos envolvidos.

Todas as informações foram consolidadas através das atividades realizadas e registradas no diário de campo. Após a gravação das entrevistas, as falas foram transcritas na íntegra e armazenadas, para posteriormente subsidiar a categorização, seguindo a técnica de análise temática conforme Minayo (2010).

Essa vivência faz parte de uma pesquisa maior intitulada "Formação de profissionais para o Programa Saúde na Escola: uma pesquisa-ação", submetida ao Comitê de Ética e Pesquisa da Universidade Estadual do Ceará (UECE), Certificado de Apresentação para Apreciação Ética oํ 7139117.0.0000.5534. Foi elaborado o Termo de Consentimento Livre e Esclarecido para os participantes da pesquisa, a qual adotou a Resolução no 466/2012, do Conselho Nacional de Saúde (CNS), que garante proteção aos seres humanos participantes de pesquisas científicas respeitando sua dignidade.

\section{Resultados e discussões}

\subsection{Fase I - Diagnóstico dos conhecimentos dos diretores escolares acerca do PSE}

Nesta fase, coletaram-se as informações obtidas através da aplicação de um questionário respondido por dez diretores de escolas para levantamento dos conhecimentos referentes ao PSE. As questões trataram sobre o PSE: 1) Conhecimento sobre o PSE; 2) Objetivos do PSE; 3) Ações realizadas no PSE; 4) Profissionais responsáveis para a execução do PSE; e 5) Função dos profissionais na atividade do PSE.

\subsubsection{Perfil dos participantes}

O presente estudo contou com a participação de dez diretores de escolas públicas que estavam iniciando suas atividades no PSE das escolas selecionadas. O perfil dos profissionais é representando no Gráfico 1, sendo $100 \%$ dos diretores representados pelo sexo feminino. 
Gráfico 1 - Participantes quanto ao sexo

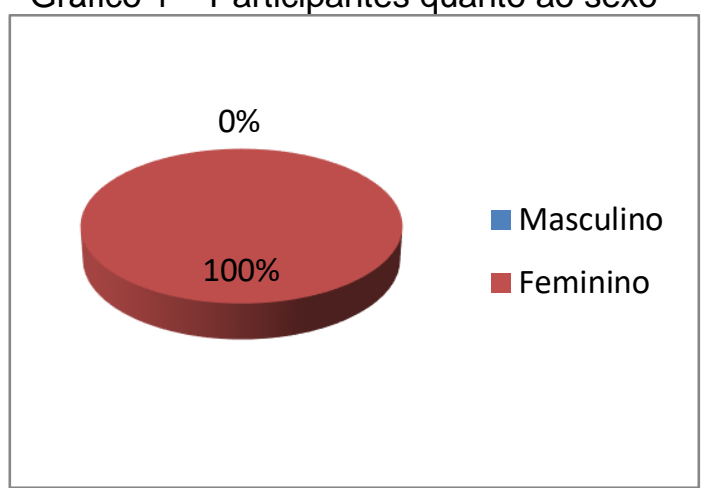

Fonte: Elaboração própria (2017).
Gráfico 2 - Participantes quanto à faixa etária

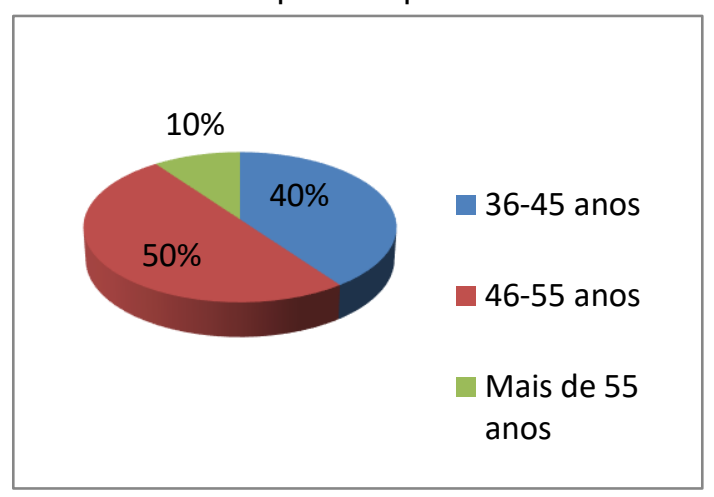

Fonte: Elaboração própria (2017).

\subsubsection{Conhecimentos dos diretores escolares acerca da existência do PSE}

A primeira questão do questionário tratou sobre o conhecimento dos profissionais acerca da existência do PSE. As respostas foram objetivas e diretas. No total das respostas (Gráfico 3), percebe-se que $90 \%$ dos diretores sabiam que existe 0 PSE; apenas um diretor (10\%) afirmou já ter ouvido falar do PSE.

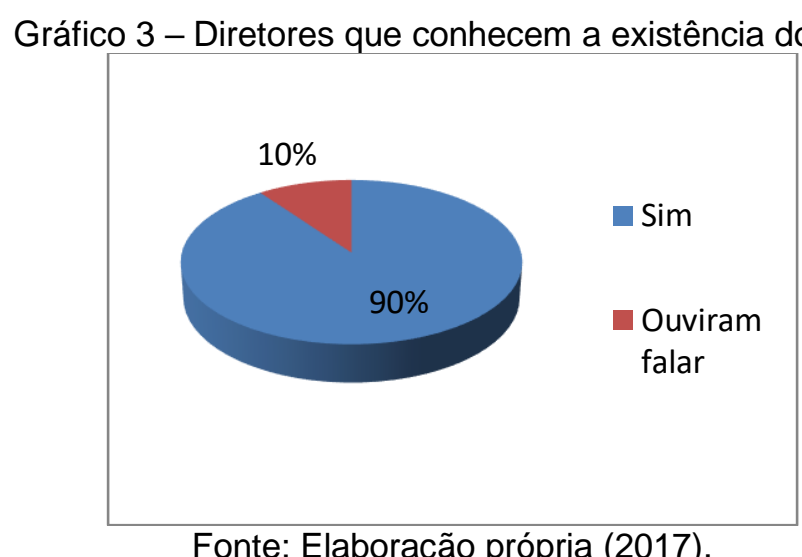

É perceptível que a maioria dos diretores conheciam a existência do programa. Isso se justifica pelo fato de o programa já existir desde 2007, tendo sido o ano de 2013 marcado pela universalização do PSE e pela ampliação das ações de promoção e atenção à saúde. 
3.1.3 Conhecimento dos diretores escolares sobre os objetivos do PSE

No segundo item do questionário, coletaram-se informações dos profissionais sobre os conhecimentos a respeito dos objetivos do PSE. Como se pode observar pelas considerações a seguir, alguns diretores apresentaram ter noção dos objetivos do PSE, gerando uma gama de respostas de caráter discursivo. Porém, outros apresentaram particularidades que de fato caracterizam o PSE, no entanto ainda de forma fragmentada, contemplando pequenas dimensões do programa. Conforme alguns discursos:

O PSE tem como objetivo realizar uma parceria entre saúde e educação, buscando melhorias na qualidade de vida dos educandos. (DIRETOR 1).

O PSE procura promover a melhoria da saúde nas crianças e adolescentes e dá acesso aos alunos com o atendimento especializado que muitas vezes eles não conseguem no seu cotidiano. (DIRETOR 2).

O objetivo do PSE é realizar o atendimento à comunidade escolar do seu território com melhor qualidade. (DIRETOR 3).

Nota-se que alguns discursos ainda se distanciam do que seriam os objetivos do PSE, uma vez que os diretores percebem como algo apenas para informar ou realizar procedimentos, e não como um espaço para a construção de conhecimento e promoção da saúde. O objetivo do PSE é contribuir para a formação integral dos estudantes por meio de ações de saúde integral ao escolar (prevenção, promoção e atenção à saúde, bem como acesso aos diversos níveis de atenção da rede de saúde), visando ao enfrentamento das vulnerabilidades que põem em risco o pleno desenvolvimento de crianças e jovens da rede pública de ensino brasileiro (BRASIL, 2009b; FERREIRA et al., 2014). As respostas aos questionamentos para os profissionais sobre os objetivos do PSE mostraram-se vagas, demonstrando que eles não conhecem o real objetivo do programa.

\subsubsection{Ações realizadas no PSE}

Como forma de compreender se os diretores conheciam as ações que devem ser realizadas no programa, o quarto item do questionário interrogou os profissionais sobre as ações realizadas no PSE. Como se pode observar nas afirmações adiante, os participantes revelaram parcialmente uma noção das ações contidas no PSE: 
Nas visitas às escolas, os profissionais de saúde avaliam os estudantes, trabalham com a prevenção de doenças e realizam palestras com informações sobre saúde e bem-estar do educando. (DIRETOR 1).

[...] é realizado com os estudantes o controle do peso e a avaliação da pressão arterial. (DIRETOR 5).

[...] Os profissionais de saúde realizam exame físico dos estudantes e ações de saúde bucal. (DIRETOR 9).

Os componentes listados e contemplados no documento nacional do PSE são: a) avaliação das condições de saúde das crianças, adolescentes e jovens que estão na escola pública; b) promoção da saúde e de atividades de prevenção; c) educação permanente e capacitação dos profissionais da educação e da saúde de jovens; d) monitoramento e avaliação da saúde dos estudantes; e e) monitoramento e avaliação do programa (BRASIL, 2015b, 2015c, 2016).

Assim, para a efetivação das ações educativas, o envolvimento de todos os atores é condição ímpar para o pleno exercício da saúde, contudo, no contexto que envolve o PSE, um dos desafios para a efetivação das ações é a capacitação dos profissionais das escolas para trabalharem com a educação para a saúde.

\subsubsection{Profissionais responsáveis para a execução do PSE}

O quinto item do questionário apresentou como o intuito verificar o conhecimento dos participantes sobre quais são os profissionais responsáveis para a execução das atividades do PSE. Buscando um entendimento, pode-se perceber nas respostas a importância desta investigação, demonstrado na apresentação dos discursos de cinco diretores de escolas, que consideram que as ações do PSE são apenas de responsabilidade dos profissionais de saúde.

[...] Enfermeiros e técnicos de enfermagem são os profissionais que devem realizar as atividades do programa. (DIRETOR 5).

[...] Psicólogo, fonoaudiólogo, terapeuta ocupacional, nutricionista e fisioterapeuta devem realizar as ações do PSE. (DIRETOR 6).

[...] Enfermeiros e agentes comunitários de saúde são os responsáveis por realizarem as ações do PSE. (DIRETOR 8).

[...] Enfermeiro, agente de saúde, médico, nutricionista, dentista e equipe do Núcleo de Apoio a Saúde da Família (NASF). (DIRETOR 2). 
A partir da análise de alguns relatos acima dos diretores de escolas, nota-se que eles acreditam que o PSE é realizado apenas quando os profissionais de saúde vão até a escola, sem que estes também tenham o compromisso de dar continuidade, dentro de seu campo de atuação e saber, às ações contempladas pelo programa. Assim, considera-se uma ausência de trabalho em equipe de fato integrado à escola.

Dando continuidade aos discursos, dois diretores incluíram os profissionais das escolas na realização das ações do PSE, conforme os relatos abaixo:

\footnotetext{
Os profissionais que devem participar da realização das ações do PSE são: profissionais da unidade básica de saúde, equipe do NASF, diretores e coordenadores da escola. (DIRETOR 1).
}

Devem participar das ações do PSE todos os profissionais envolvidos na saúde e educação do município, afinal é uma parceria na melhoria da qualidade de vida dos estudantes. Os profissionais são: diretores, coordenadores, professores e merendeiras da escola. Enfermeiros, dentistas, médicos e agentes comunitários de saúde da unidade básica de saúde. (DIRETOR 4).

Além da participação do corpo docente e diretores das escolas na execução do PSE, também podem estar envolvidos os demais membros da comunidade escolar, ou seja, assistentes administrativos, secretários, profissionais responsáveis pela merenda, cantina e limpeza, familiares e pessoas da comunidade (BRASIL, 2011).

Desse modo, os diretores e outros profissionais da escola, tendo o apoio da saúde, terão segurança para abordar diariamente temas que ajudam na prevenção de doenças e promoção de saúde, promovendo saúde e qualidade de vida aos estudantes (SANTOS; FERREIRA; SIMÕES, 2016).

\subsection{Fase II - Planejamento/Ação: formação dos diretores escolares para o PSE}

A ação da fase II consistiu em uma ação no formato de formação com os diretores escolares. Em suma, as atividades que elucidaram a formação aqui proposta foram elaboradas mediante o resultado do diagnóstico do conhecimento dos diretores acerca do PSE (fase I), que subsidiou uma descrição dos conhecimentos dos profissionais, permitindo que a intervenção atuasse no aprofundamento das dúvidas dos profissionais. Dessa forma, a formação foi realizada um mês após a primeira fase, tempo em que a primeira pesquisadora deste artigo analisou as respostas do questionário, diagnosticou os conhecimentos dos profissionais e preparou a formação.

Educação \& Formação, Fortaleza, v. 5, n. 14, p. 195-215, maio/ago. 2020

DOI: https://doi.org/10.25053/10.25053/redufor.v5i14.898

http://seer.uece.br/redufor 
Assim, para a realização da formação, os conteúdos abordados foram baseados nos materiais publicados na Biblioteca Virtual em Saúde do Ministério da Saúde sobre o PSE: Caderno do Gestor do PSE (2015); Passo a passo PSE: tecendo caminhos da intersetorialidade (2011); Guia de sugestões de atividades: semana saúde na escola (2013); Caderno de atenção básica: saúde na escola (2009); Portaria interministerial no 1.055, de 25 de abril de 2017; Triagem da acuidade visual: manual de orientação (2008); Cadernos temáticos do PSE: saúde ocular (2016); Caderno temático: verificação da situação vacinal - versão preliminar (2015); Caderno temático: práticas corporais, atividade física e lazer - versão preliminar (2015).

Os itens observados na fase II durante a execução da formação com os profissionais foram: envolvimento, motivação, dúvidas sobre o PSE, trabalho em equipe/interação, capacidade de construir conhecimento e interesse dos diretores pela formação. Nessa perspectiva, a formação ocorreu no auditório da Secretaria Municipal de Saúde de São Benedito-CE, durante um dia, nos turnos manhã e tarde, no mês de setembro de 2017, perfazendo um total de dez horas de carga horária de formação, ministrada pela primeira autora da pesquisa, buscando o desafio de elaborar e desenvolver uma formação empolgante e motivadora.

Quadro 1 - Programação da formação de diretores escolares para o PSE

\begin{tabular}{|c|c|}
\hline Manhã & Tarde \\
\hline $\begin{array}{l}\text { 07h - Acolhimento e integração dos diretores } \\
\text { escolares. }\end{array}$ & $\begin{array}{l}\text { 13h - O Programa Saúde na Escola: breve histórico } \\
\text { da implantação do PSE no Brasil e no município de } \\
\text { São Benedito-CE; Diretrizes e objetivos do PSE; } \\
\text { Implementação, execução e gestão do PSE. }\end{array}$ \\
\hline $\begin{array}{l}\text { 07h15 - Abertura da formação. Exposição } \\
\text { dialogada: princípios da saúde coletiva. }\end{array}$ & $\begin{array}{l}\text { 14h15 - Áreas temáticas das ações no âmbito do } \\
\text { PSE. }\end{array}$ \\
\hline 08h - Exposição dialogada: promoção da saúde. & 15h - Intervalo. \\
\hline $\begin{array}{l}\text { 08h40 - Exposição dialogada: humanização e } \\
\text { cuidado na saúde escolar. }\end{array}$ & $\begin{array}{l}\text { 15h15 - Saúde ocular dos estudantes e benefícios } \\
\text { da prestação continuada. }\end{array}$ \\
\hline 09h30 - Intervalo - Cofee break. & $\begin{array}{l}15 \mathrm{~h} 40 \text { - Agenda proteger e cuidar da saúde do } \\
\text { adolescente no âmbito do PSE. }\end{array}$ \\
\hline $\begin{array}{l}\text { 09h50 - Exposição dialogada: a integralidade } \\
\text { como princípio articulador no Sistema Unico de } \\
\text { Saúde (SUS) e como eixo norteador das ações de } \\
\text { educação em saúde. }\end{array}$ & 16h - Fragilidades na realização das ações do PSE. \\
\hline $\begin{array}{l}\text { 11h - Exposição dialogada: Intersetorialidade } \\
\text { para efetivação do PSE. }\end{array}$ & $\begin{array}{l}16 \text { h30 - Destacando boas experiências do PSE no } \\
\text { Brasil. Atividade em grupo: leitura dialogada de } \\
\text { artigos científicos com experiências do PSE em } \\
\text { outros municípios. }\end{array}$ \\
\hline 12h - Intervalo para & $\mathbf{1 7 h}$ - Encerramento das atividades. \\
\hline
\end{tabular}

Fonte: Elaboração própria (2017).

Educação \& Formação, Fortaleza, v. 5, n. 14, p. 195-215, maio/ago. 2020

DOI: https://doi.org/10.25053/10.25053/redufor.v5i14.898

http://seer.uece.br/redufor 
Durante a formação, os diretores escolares apresentaram diversas dúvidas sobre os temas abordados no PSE. Dificuldades que surgiram devido a esses profissionais não trabalharem na área da saúde, sendo então uma atuação considerada nova e desafiadora para eles no tocante à construção da autonomia profissional para o desenvolvimento da nova atividade (BEGO, 2016).

No estudo realizado por Zancha et al. (2013), os autores trazem esta abordagem ao afirmarem que o ensino da temática saúde tem sido uma dificuldade aos profissionais da educação no sentido de garantir uma aprendizagem efetiva e transformadora de hábitos e atitudes de vida aos estudantes. Assim, concordam que não se trata apenas de ter conhecimento para repassar conteúdos, mas a abordagem em si e as dúvidas que são geradas requerem uma preparação adequada a esses indivíduos.

Outros questionamentos foram realizados sobre o planejamento das ações dos profissionais da saúde junto aos profissionais das escolas. Como fariam para combinar todas essas ações que tinham que ser realizadas. Porém, uma das maiores dúvidas dos participantes da formação foi realmente compreender como funcionam o PSE e as articulações entre estes dois setores: saúde e educação na prática. Surgiram também muitas dúvidas relacionadas ao financiamento do programa e sistema de monitoramento das ações (sistema de inclusão dos dados da saúde [e-SUS] da atenção básica e tempo para serem inseridas as informações).

Outra dúvida importante foi sobre o teste de acuidade visual utilizando o teste de Snellen. Os diretores argumentaram que quem tinha que realizar o teste era apenas o oftalmologista ou o enfermeiro. Contudo, de acordo com as diretrizes do Ministério da Saúde, qualquer profissional de saúde ou da escola capacitado para realizar o teste de Snellen pode executá-lo. Segundo a Portaria no 254, de 24 de julho de 2009, a triagem da acuidade visual pode ser realizada por profissionais de saúde e de educação.

Os diretores também se mostraram sensibilizados quanto à importância da realização das ações em conjunto com os profissionais de saúde, sobre os objetivos do PSE e suas implicações, bem como reconheceram o seu papel e responsabilização nesse cenário alcançando a perspectiva interdisciplinar.

Nesse sentido, a interação e a troca de saberes durante a formação favoreceram ainda o fortalecimento dos profissionais como sujeitos sociais, além de suscitarem a 
tomada de consciência, pois, ao interagirem com outros profissionais que vivem situações semelhantes, as representações desses sujeitos foram reconhecidas ou transformadas.

No tocante aos saberes adquiridos, evidenciou-se que a intervenção educativa gerou esclarecimento pertinente às possibilidades no espaço de trabalho para a realização das atividades do programa. Os achados também apontam que ocorreu um processo de aprendizagem coletiva entre os profissionais.

Ceccim (2005) afirma que, através da educação, da formação permanente, os indivíduos são atores ativos das cenas de formação e trabalho (produtos e produtores das cenas, em ato). Os eventos em cena produzem diferença, afetam, modificam, produzindo abalos no "ser sujeito", colocando as pessoas em permanente produção. $O$ permanente é o aqui e agora, diante de problemas reais, pessoas reais e equipes reais.

Nessa óptica, educação e conhecimento possuem uma grande inter-relação, uma vez que a prática educativa se constitui numa situação de conhecimento que se põe em prática e é política porque há uma reflexão nessa prática (FREIRE, 2011). Nessa perspectiva, de forma geral, a repercussão da realização da formação foi positiva, pois permitiu o reconhecimento da importância da execução das ações do PSE nas práticas no serviço.

\subsection{Fase III - Entrevista em grupo com os diretores escolares}

A fase III da pesquisa consistiu na entrevista em grupo com os profissionais participantes da formação, como forma de avaliar a contribuição do processo de formação na prática dos participantes. Utilizou-se um instrumento para nortear o andamento da entrevista em grupo.

Nesse momento, reuniram-se novamente os dez diretores das escolas para a realização da entrevista em grupo, que ocorreu um mês após a formação, tempo utilizado para os profissionais realizarem algumas atividades do PSE no seu território, aplicando a teoria aprendida na formação durante a prática cotidiana do PSE. Esse tempo foi proposto e acordado entre os diretores e a primeira pesquisadora deste estudo.

Os profissionais registraram suas opiniões no grupo, respondendo individualmente ou em complementação a falas dos demais participantes, respeitando o 
direito de fala dos pares e tecendo uma discussão coletiva. As entrevistas foram gravadas e posteriormente transcritas.

Os resultados da fase III foram divididos em seis categorias, sendo definidas de acordo com o instrumento da entrevista em grupo, que baseou a discussão da primeira pesquisadora junto aos profissionais. As seis categorias definidas foram: avaliação da formação oferecida acerca do PSE; conhecimentos dos diretores escolares acerca do PSE, antes e após a formação; contribuição da formação com a prática profissional no PSE; contribuição da formação no crescimento pessoal; contribuição da formação na relação com os colegas e usuários do PSE; e sugestões para a formação tornar-se mais resolutiva ao que se propõe.

\subsubsection{Avaliação da formação oferecida acerca do PSE}

Como se pode observar pelas considerações a seguir, os diretores escolares relataram que a formação foi relevante para direcionar a forma como as atividades do PSE seriam desenvolvidas, assinalando que há sempre a necessidade de o profissional estar procurando qualificar-se e aprimorar os conhecimentos já existentes. Seguem adiante alguns discursos:

\footnotetext{
A metodologia da formação foi excelente, como também o material e a docente, onde despertou de nós o envolvimento e aprendizado sobre o PSE, nos direcionando para o exercício das atividades no PSE. Mas o tempo foi pouco, gostaria que tivéssemos mais momentos como esse. (DIRETOR 7).

Muito boa, prática e de fácil entendimento. Durante toda a formação, foi aliada a teoria com a prática. Gostaria que formações sobre o PSE fossem realizadas mais vezes e que abrangessem todos os diretores, e não apenas alguns. Por ser um momento muito rico de aprendizado, todos devem participar. (DIRETOR 6).

Com a formação, pude conhecer e vivenciar o PSE. Foi repassada de forma clara. A ministrante mostrou-se de forma segura ao abordar o conteúdo, utilizando umas metodologias dinâmicas, material com qualidade e ambiente acolhedor, propiciando um melhor aprendizado. (DIRETOR 9).
}

No início da formação, foi necessária a realização de ações que estimulassem a curiosidade dos profissionais, de modo que pudessem buscar cada vez mais informações sobre o programa e condução das estratégias executadas, esclarecendo as dúvidas quanto ao programa e às atribuições de cada ator envolvido. 
Ramos et al. (2013) descrevem a formação como um espaço importante para o diálogo, em que as pessoas se expressam, escutam os outros e a si mesmas, estimulando a autonomia dos sujeitos pela troca de informações e reflexão para a ação, mediando aprendizagens recíprocas e/ou associando competências, pois todos os participantes da roda possuem poderes iguais sobre os territórios de que falam.

Os diretores de escolas apontaram em seus relatos que a formação foi excelente, prática, objetiva, dinâmica e de fácil entendimento, direcionando o exercício das atividades do PSE e aliando sempre teoria e prática, que apresentou recursos acessíveis, material com qualidade, ambiente acolhedor e espaço adequado, atendendo à demanda dos cursistas. Reconheceram que necessitam de qualificação para melhorar o trabalho e que poderiam ser realizadas outras formações do PSE, mas que abrangessem todos os diretores das escolas do município.

\title{
3.3.2 Conhecimentos dos diretores escolares acerca do PSE, antes e após a formação
}

No segundo item da entrevista, solicitou-se aos profissionais envolvidos na formação que comentassem a respeito dos seus conhecimentos sobre o PSE, antes e após a realização da formação. Seguem os comentários de alguns diretores durante a entrevista em grupo:

\begin{abstract}
Antes da formação, já ouvia falar do PSE, porém achava que as atribuições do programa eram apenas dos profissionais da área de saúde. Hoje, após a formação, compreendo que, para a realização das ações, não pode ocorrer um trabalho isolado, e sim em conjunto, em forma de parceria. (DIRETOR 2).
\end{abstract}

Antes da formação, não tinha conhecimento sobre o PSE e também não sabia de sua importância dentro das escolas, mas, após a formação, percebi as vantagens e benefícios do programa aos estudantes da rede municipal e estadual. (DIRETOR 4).

Antes da formação, não tinha conhecimento sobre o programa, como funcionava e qual a importância da participação e colaboração da escola. Após participar da formação, passei a ver a importância do trabalho de toda a equipe de outra forma: agora tenho consciência de que o trabalho não é responsabilidade só da equipe de saúde, e sim também dos profissionais que estão dentro da escola, já que o programa é uma parceria de saúde e educação. (DIRETOR 10).

Segundo o autor Fernandes (2008), o processo de aprendizagem pode caracterizar-se como reconstrutivo: vai além da atualização técnica e apela para um 
profundo enfrentamento entre velhos padrões; conduz-se mais para a construção de novas metas, políticas, normas e formas de organização e comunicação no trabalho do que para a simples modificação do velho.

Assim, após a formação, ficou claro o entendimento dos profissionais sobre o PSE, conseguindo aplicar na prática o conteúdo aprendido, melhorando a qualidade na realização das atividades.

\title{
3.3.3 Contribuição da formação com a prática profissional no PSE
}

Após a formação, os profissionais envolvidos no PSE puderam refletir sobre sua prática e, a partir daí, confrontar ideias, experiências vivenciadas entre eles e fazer uma associação com os problemas enfrentados na prática.

\begin{abstract}
A formação contribuiu muito na minha prática profissional, na verdade para todos os diretores de escolas. Mesmo sendo um programa que envolve as secretarias de saúde e educação, nunca tínhamos tido uma formação sobre o programa. Hoje meus conhecimentos aumentaram, melhorando minha prática profissional dentro do PSE, onde tenho um olhar diferenciado em determinadas situações com os nossos estudantes. (DIRETOR 9).
\end{abstract}

Agora eu entendi melhor como deve trabalhar com o programa dentro da escola. Hoje em dia, não espero mais pela equipe de saúde. O que já posso agilizar com o programa já vou fazendo. E em toda ação que realizo consigo refletir sobre a prática realizada, assim me sinto uma profissional que faz com eficácia o PSE. (DIRETOR 3).

Sim. A formação ajudou a conduzir minha prática profissional em concordância com referenciais teóricos consistentes repassados na formação e de repensá-los a partir da vivência junto ao programa. (DIRETOR 4).

As capacitações são necessárias para a formação de profissionais proativos, capazes de fazer reflexões sobre o trabalho e ainda de diagnosticar e solucionar problemas, de tomar decisões, de intervir no processo, de enfrentar situações em constantes mudanças (BRASIL, 2007).

Os diretores escolares apresentaram em seus discursos que, após a formação, passaram a entender seu papel dentro das atividades do PSE, conseguindo ligar a prática profissional às atividades do PSE, refletindo sobre suas práticas. Hoje apresentam um olhar diferenciado em determinadas situações, dando o suporte necessário para o acompanhamento da saúde dos estudantes.

Educação \& Formação, Fortaleza, v. 5, n. 14, p. 195-215, maio/ago. 2020 
3.3.4 Contribuição da formação sobre o PSE no crescimento pessoal dos diretores escolares

O quarto item da entrevista em grupo questionou os profissionais participantes da formação se a formação tinha contribuído no seu crescimento pessoal. Para o crescimento pessoal, é preciso desenvolver em cada um a capacidade de interpretar o cotidiano e atuar de modo a incorporar atitudes e/ou comportamentos adequados para a melhoria da qualidade de vida (BRASIL, 2011).

Todo investimento em treinamento e qualificação de pessoas, quando bem planejado e desenvolvido, é capaz de produzir mudanças positivas no desempenho das pessoas, conforme seguem os argumentos abaixo:

\begin{abstract}
A formação nos mostrou o quanto precisamos ser mais humanizados $e$ acolhedores com os estudantes, e não fazer apenas as atividades do PSE tecnicamente para cumprir com metas preconizadas. Hoje tenho um olhar mais humanizado nas ações com os estudantes. (DIRETOR 7).

Ao compartilharmos conhecimentos e experiências com outros profissionais durante a formação, pude refletir sobre minha atuação pessoal, onde pude traçar outros saberes, novas ideias e caminhos para o PSE. (DIRETOR 8).
\end{abstract}

Campos et al. (2006) consideram a humanização como um processo social e subjetivo que implica a transformação dos sujeitos e a ampliação de sua capacidade para agir nas relações, como foi identificado nos discursos de muitos participantes, conforme citado anteriormente.

De acordo com a análise dos discursos apresentados pelos diretores de escolas, a formação contribuiu positivamente no crescimento pessoal deles, pois aumentou e fortaleceu as relações afetivas entre esses profissionais; estimulou a ter atitudes reflexivas, traçando novos conhecimentos e valorizando o trabalho junto ao PSE. Os diretores conheceram as diversas facetas que englobam o programa e a sua relevância, em que obtiveram um crescimento pessoal, o qual serviu como aprendizado para a vida.

\title{
3.3.5 Sugestões para a formação sobre o PSE tornar-se mais resolutiva ao que se propõe
}

As formações precisam ser planejadas numa conjuntura que permita aos profissionais colocarem as suas contribuições, de modo que tenham a oportunidade de 
compartilhar os problemas enfrentados com relação ao PSE, as estratégias de trabalho utilizadas e as soluções que encontram no dia a dia para melhor direcionar as ações.

O último item da entrevista em grupo interrogava os profissionais sobre as sugestões deles para tornar a formação mais resolutiva para a prática no PSE. Assim, surgiram as seguintes discussões:

Acredito que o PSE é um programa bem abrangente, por esse motivo o tempo da formação deveria ser maior para discutir minuciosamente todas as questões propostas pelo programa. (DIRETOR 2).

Acho que as formações sobre o PSE deveriam ser dentro do ambiente escolar, com a presença de diretores, coordenadores, professores e alunos, para esclarecimentos mais claros sobre a importância do PSE. (DIRETOR 7).

Seria muito bom que as formações sobre o PSE atendessem a um número maior de diretores, pois apenas dez diretores participaram dessa forma. Inclusive, também seria boa a participação de professores, pois muitos desses ainda não possuem esclarecimentos acerca do programa e acham que as ações devem ser realizadas de forma isolada, sem a participação conjunta dos setores de saúde e educação. (DIRETOR 8).

É fundamental a capacitação permanente para os profissionais que atuam na escola, além da necessidade de contratação de profissionais de diversas formações, com perfil e competência para as ações de promoção da saúde (FERREIRA et al., 2014; MORORÓ, 2017).

Assim, evidencia-se, através dos discursos, que os diretores escolares apresentaram algumas sugestões, como: aumentar a carga horária da formação para assim discutir minuciosamente todas as questões propostas pelo programa; inserir diretores de outras escolas e também professores; e realizar futuras formações sobre 0 PSE no ambiente escolar para que todos profissionais da escola, inclusive estudantes, possam entender a importância do programa, já que pode colaborar com a redução da desigualdade sociocultural (LARA, 2016) e com a promoção da saúde.

\section{Considerações finais}

Durante o percurso do estudo, verificou-se o perfil dos participantes da pesquisa, diagnosticando-se o conhecimento deles acerca do PSE, quando se detectou que os diretores escolares conheciam o PSE, porém ainda não entendiam totalmente 0 sentido da política do programa, tendo a necessidade de realizar uma formação com

Educação \& Formação, Fortaleza, v. 5, n. 14, p. 195-215, maio/ago. 2020

DOI: https://doi.org/10.25053/10.25053/redufor.v5i14.898

http://seer.uece.br/redufor 
esses profissionais. Desse modo, executou-se posteriormente uma formação sobre as características do programa; em seguida, analisou-se o processo de formação; e, por fim, realizou-se a avaliação da contribuição do processo de formação para os diretores envolvidos.

Nesse contexto, empreendeu-se uma análise quanto às contribuições que a realização de uma formação concebeu frente às ações do PSE, partindo da reflexão da realidade, elaborada e pensada na simplicidade didática, para melhor compreensão do público-alvo, estruturada para apoiar os profissionais que iniciaram suas atividades no PSE. Nessa perspectiva, o envolvimento dos diretores em uma pesquisa-ação trouxe uma reflexão crítica sobre a realidade em que estão inseridos, após diagnóstico dos conhecimentos dos profissionais sobre as características do PSE. Dessa forma, no decorrer desse processo, construíram-se não só conhecimentos individuais e coletivos, mas também novas habilidades e atitudes, que propiciaram a ressignificação de valores e a transformação de situações indesejadas.

Destaca-se também que a formação trouxe envolvimento ativo da primeira pesquisadora deste estudo com os profissionais, propiciando a redução de distâncias entre eles, compreendendo uma pesquisa em que se investigaram as causas e consequências para a resolução de vários problemas diagnosticados. Contudo, ressalta-se que não basta abrir espaços para promover saúde, fazendo-se mister a necessidade de realização de formações sobre PSE para os profissionais desenvolverem habilidades para lidar com os processos saúde-doença, importantíssimos para a efetivação das ações.

Dessa maneira, investimentos em mais formações sobre o PSE contribuem para a transformação das práticas profissionais, pedagógicas e de saúde para a organização dos serviços, constituindo-se como uma estratégia essencial para o aprimoramento das ações do PSE.

\section{Referências}

BEGO, A. Políticas públicas e formação de professores sob a perspectiva da racionalidade comunicativa: da ingerência tecnocrata à construção da autonomia profissional. Educação \& Formação, Fortaleza, v. 1, n. 2, p. 3-24, 2016. Disponível em: https://revistas.uece.br/index.php/redufor/article/view/98. Acesso em: 20 mar. 2020. 
BRASIL. Caderno do gestor do PSE. Brasília, DF: Ministério da Saúde, 2015a.

BRASIL. Cadernos temáticos do PSE: práticas corporais, atividade física e lazer. Brasília, DF: Ministério da Saúde, 2015b.

BRASIL. Cadernos temáticos do PSE: saúde ocular. Brasília, DF: Ministério da Saúde, 2016.

BRASIL. Cadernos temáticos do PSE: verificação da situação vacinal. Brasília, DF: Ministério da Saúde, 2015c.

BRASIL. Decreto no 6.286, de 5 de dezembro de 2007. Institui o Programa Saúde na Escola - PSE, e dá outras providências. Diário Oficial [da] República Federativa do Brasil, Poder Executivo, Brasília, DF, 6 dez. 2007.

BRASIL. Instrutivo PSE. Brasília, DF: Ministério da Saúde, 2011.

BRASIL. Política Nacional da Promoção da Saúde. Brasília, DF: Ministério da Saúde, 2006.

BRASIL. Portaria no 254, de 24 de julho de 2009. Estabelece diretrizes para a operacionalização do acesso às consultas oftalmológicas e o fornecimento de óculos, para a viabilização plena do Projeto Olhar Brasil e as disposições transitórias para a Ação Emergencial do PBA - Programa Brasil Alfabetizado. Diário Oficial [da] República Federativa do Brasil, Poder Executivo, Brasília, DF, 25 jul. 2009a.

BRASIL. Resolução no 466, de 12 de dezembro de 2012. Diretrizes e normas regulamentadoras de pesquisas em seres humanos. Diário Oficial [da] República Federativa do Brasil, Poder Executivo, Brasília, DF, 13 dez. 2012.

BRASIL. Saúde na escola. Brasília, DF: Ministério da Saúde, 2009b.

BRASIL. Triagem de acuidade visual manual de orientação. Brasília, DF: Ministério da Saúde e Ministério da Educação, 2008.

CAMPOS, E. F. et al. Os desafios atuais para educação permanente no SUS. In: BRASIL. Cadernos de RA. Saúde. Recursos Humanos em Saúde. Brasília, DF: Ministério da Saúde, 2006. p. 39-43.

CECCIM, R. B. Educação permanente em saúde: desafio ambicioso e necessário. Interface: Comunicação, Saúde, Educação, Botucatu, v. 9, n.16, p. 61-177, 2005. Disponível em: http://www.scielo.br/pdf/icse/v9n16/v9n16a13.pdf. Acesso em: 20 mar. 2020.

FERNANDES, R. M. C. F. Educação permanente: uma dimensão formativa no Serviço Social. 2008. Tese (Doutorado em Serviço Social) - Programa de Pós-Graduação em Serviço Social, Universidade Católica do Rio Grande do Sul, Porto Alegre, 2008. 
FERREIRA, H. S. Educação Física e saúde nas escolas públicas municipais de Fortaleza: uma proposta de ensino. Fortaleza: UECE, 2012.

FERREIRA, I. C. et al. Percepções de gestores locais sobre a intersetorialidade no Programa Saúde na Escola. Revista Brasileira de Educação, Rio de Janeiro, v. 19, n. 56, p. 61-76, 2014. Disponível em: http://www.scielo.br/pdf/rbedu/v19n56/v19n56a04.pdf. Acesso em: 20 mar. 2020.

FIALHO, L. M. F.; SANTANA, J. R.; BRANDENBURG, C. La calidad de vida infantil y sus dimensiones: percepción de escolares. Barbarói, Santa Cruz do Sul, n. 45, v. 2, p. 227-241, 2015. Disponível em: https://online.unisc.br/seer/index.php/barbaroi/article/view/5065. Acesso em: 20 mar. 2020.

FREIRE, P. R. N. A importância do ato de ler: em três artigos que se completam. 51. ed. São Paulo: Cortez, 2011.

LARA, A. M. Políticas de redução da desigualdade sociocultural. Educação \& Formação, Fortaleza, v. 1, n. 3 , p. 140-153, 2016 . Disponível em: https://revistas.uece.br/index.php/redufor/article/view/118. Acesso em: 20 mar. 2020.

MINAYO, M. C. S. O desafio do conhecimento: pesquisa qualitativa em saúde. 12. ed. São Paulo: Hucitec: Abrasco, 2010.

MORORÓ, L. A influência da formação continuada na prática docente. Educação \& Formação, Fortaleza, v. 2, n. 4, p. 36-51, 2017. Disponível em: https://revistas.uece.br/index.php/redufor/article/view/122. Acesso em: 20 mar. 2020.

RAMOS, L. S. et al. Estratégia de Roda de Conversa no processo de educação permanente em saúde mental. Revista Rene, Fortaleza, v. 14, n. 4, p. 845-853, 2013. Disponível em: https://www.redalyc.org/pdf/3240/324028459022.pdf. Acesso em: 20 mar. 2020.

SANTOS, M. A.; FERREIRA, H.; SIMÕES, L. L. Saberes da docência aprendidos no Pibid: um estudo de caso com professores supervisores de Educação Física. Educação \& Formação, Fortaleza, v. 1, n. 2, p. 104-120, 2016. Disponível em: https://revistas.uece.br/index.php/redufor/article/view/103. Acesso em: 20 mar. 2020.

THIOLLENT, M. Metodologia da pesquisa-ação. São Paulo: Cortez, 2011.

ZANCHA, D. et al. Conhecimento dos professores de Educação Física escolar sobre a abordagem Saúde Renovada e a Temática Saúde. Conexões, Campinas, v. 11, n. 1, p. 204-217, 2013. Disponível em: https://www.periodicos.sbu.unicamp.br/ojs/index.php/conexoes/article/view/8637638. Acesso em: 20 mar. 2020. 
Karlla da Conceição Bezerra Brito Veras (Fortaleza, Ceará, Brasil)

Universidade Estadual do Ceará (UECE), Programa de Pós-Graduação em Saúde Coletiva, Doutorado em Cuidados Clínicos em Saúde

Doutoranda do Programa de Pós-Graduação de Cuidados Clínicos em Enfermagem e Saúde da UECE, mestra em Ensino na Saúde pela UECE, apresentando conhecimento no uso de Metodologias Ativas em sala de aula, especialista em Obstetrícia pela Faculdade Metropolitana de Fortaleza (Fametro) e graduada em Enfermagem pela Universidade de Fortaleza (Unifor). Concursada na Prefeitura Municipal de São Benedito-CE no cargo de enfermeira da Estratégia Saúde da Família, onde atuou exercendo o cargo de coordenadora do Programa Saúde na Escola (PSE) e Núcleo de Apoio a Saúde da Família (NASF) na Secretaria Municipal de Saúde de São Benedito-CE entre 2014 e 2017.

Contribuição de autoria: Elaborou a introdução, metodologia e coleta de dados.

Lattes: http://lattes.cnpq.br/5269064271273231.

E-mail:karlla_veras@hotmail.com.

Heraldo Simões Ferreira (Fortaleza, Ceará, Brasil)
Universidade Estadual do Ceará (UECE), Programa de Pós-Graduação em Cuidados Clínicos
em Enfermagem e Saúde, Curso de Mestrado e Doutorado em Educação
É professor adjunto da UECE desde 2003. É professor do Programa de Pós-Graduação em Educação
(PPGE) da UECE (mestrado e doutorado em Educação), docente e vice-coordenador do Curso de
Mestrado Profissional Ensino da Saúde (CMEPES) da UECE. Coordena o curso de graduação em
Educação Física a Distância da UECE/UAB; a especialização em Artes Marciais, Esportes de Combate
e Lutas da UECE; e o projeto de extensão Núcleo de Danças e Lutas (Nudal) da UECE. É faixa preta de
Karatê 60 Grau (CBK/FCK). É líder do Grupo de Estudos e Pesquisa em Educação Física Escolar
(Gepefe) da UECE. É conselheiro no Conselho Regional de Educação Física (CREF5).
Contribuição de autoria: Analisou os dados e realizou a revisão final.
Lattes: http://lattes.cnpq.br/4687823647729315.
E-mail: heraldo.simoes@uece.br.

Lídia Andrade Lourinho (Fortaleza, Ceará, Brasil)
Universidade Estadual do Ceará (UECE), Programa de Pós-Graduação em Saúde Coletiva,
Mestrado Profissional Ensino na Saúde

Doutora em Saúde Coletiva pela UECE/UFC/Unifor e mestra em Educação em Saúde pela Unifor. Pedagoga, fonoaudióloga e psicopedagoga. Pesquisadora do Laboratório de Saúde nos Espaços Educacionais com foco na Educação em Saúde e na Formação em Saúde, ligado ao doutorado em Saúde Coletiva da Universidade de Fortaleza (Unifor). Bolsista de doutorado da Fundação Cearense de Apoio ao Desenvolvimento Científico e Tecnológico (Funcap).

Contribuição de autoria: Apresentou a discussão dos resultados.

Lattes: http://lattes.cnpq.br/6662326867963958.

E-mail: lidiandrade67@gmail.com.

Editora responsável: Lia Machado Fiuza Fialho

Pareceristas ad hoc: Gustavo Cunha de Araújo e Cristine Brandenburg

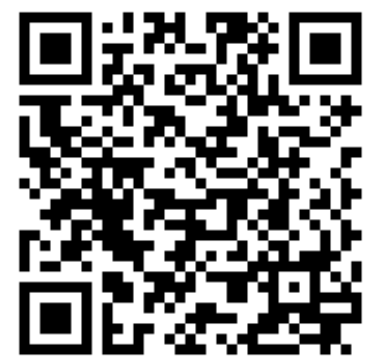

Recebido em 09 de janeiro de 2019.

Aceito em 25 de julho de 2019.

Educação \& Formação, Fortaleza, v. 5, n. 14, p. 195-215, maio/ago. 2020

DOI: https://doi.org/10.25053/10.25053/redufor.v5i14.898

http://seer.uece.br/redufor 